before the end of the six months or before he says you are ready, you will have to get the agreement of the hospital managers."

Para 4: "If you think you should be allowed to leave hospital, you should talk to your doctor. If he thinks you should stay, but you still want to leave, you can ask the hospital managers to let you go. You should write to them to ask them to do this."

This clearly indicates that a patient detained in the hospital on Section 37 can apply for his discharge to the hospital managers within the first six months of his detention. I was unable to find any reference to this effect in the Mental Health Act 1983 except in Section 23, sub section 4 which is rather vague and unclear about the powers of the hospital managers in discharging patients detained on Section 37.

I had an opportunity to discuss this issue with hospital managers and my consultant, who are all in agreement that a patient detained on Section 37 can apply to hospital managers for their discharge within the first six months and the hospital managers will ask for a psychiatric report from the responsible medical officer.

S. Duran!

Moorhaven Hospital

Bittaford, Ivybridge

S. Devon PL21 OEX

\section{Care of the pregnant drug addict}

\section{DeAR Sirs}

Much of Dr Riley's information (Bulletin, November $1987,11,362-365$ ) about the care of the pregnant drug addict is useful but some of it is confused and incomplete. The subject is becoming increasingly important and medical and paramedical staff caring for pregnant women are making errors and misjudgements precisely because of such incomplete and misleading advice.

Dr Riley tells us that because more people now take drugs on a recreational basis, "a smaller proportion of addicts show the full-blown picture of physical and mental deterioration associated with addiction in the past". Unfortunately, she does not differentiate between these very different patients. What she describes throughout is largely pregnancy in a 'street addict' who lives an illegal life and is likely, often simply as a result of this, to have a chaotic lifestyle and to suffer from malnutrition and infection. Like most of the literature on the subject, Dr Riley does not discuss healthy addicts who have regular supplies of clean drugs. As a result of this customary omission, a whole new batch of myths has developed.

The statement that "addiction of any serious degree nearly always implies the abuse of multiple drugs" is not true. There are addicts who will take any drug that they can get at any time but Dr Riley seems to imply that all heavy addicts are of this kind, which they are not. Many heavy addicts who are unable to afford enough of the drug to which they are addicted (usually an opiate) to satisfy their addiction try to dull the withdrawal symptoms by using other drugs, often barbiturates or amphetamines, which are cheaper on the black market. If they can get enough opiate, they stop using other drugs. Also, let us not forget that 'street heroin' is often 'cut' with other drugs (along with flour, brick dust etc.) to conceal the fact that it contains so little heroin. These drugs may show up in a urine test but the addict herself has almost certainly been seeking only one drug and may be unaware of their presence.

What of the opiate addict who has a clean supply of drugs and proper medical care? Dr Riley seems to include her with the others, yet she is likely to be in good, often blooming, health. I can find no evidence that she is more likely than any other healthy mother to have a baby who is small-fordates, premature or stillborn, though she may have an addicted baby. I have recently had a patient, a stable addict expecting her first baby after 15 years of stable marriage, who was badly frightened by obstetric and psychiatric staff. They told her repeatedly that she would have a premature baby and might well lose it. To encourage her, I took a bet with her that she would not. She delivered an $8 \mathrm{lb}$ baby at term. Ignorance on the part of her advisers, which could have come from reading Dr Riley's article had it not preceded it, caused that mother severe and unnecessary distress.

Dr Riley describes "physical complications" but again does not say that these are caused not by the drugs themselves but by a chaotic lifestyle dominated by the search for illegal drugs. Those whose lives and drug-taking are stable do not suffer from these complications. And although she refers to "withdrawal symptoms" in babies, she seems to think that adults take drugs only for fun. They may have started that way but once addicted, there is little fun for them. It is true that pregnancy can be a stimulus to stop taking drugs, sometimes permanently. Many chronic addicts manage to give up drugs during pregnancy because, like all normal parents, they want to do their best for their babies, and perhaps also to evade the social services.

Regarding the baby, Dr Riley mentions neither that the incidence and severity of withdrawal symptoms vary nor that some doctors believe that addicted babies do better on reducing doses of opiate than they do if given major tranquillisers. Many addict mothers believe this too and keep their babies away from doctors, sometimes treating them themselves with opiates until the infant is drug-free. Morally, this can be a responsible course of action but clearly it is dangerous. The mother embarks on it only because she has no confidence in her professional advisers or believes that they are hostile to her and may remove the child, or else simply because she dislikes the effect of chlorpromazine on her baby and believes that it is harmful. Also Dr Riley's injunction that only those on very low doses of methadone should breast-feed is based on unproven theory. Many addict mothers, and sometimes their doctors too, believe that breast-feeding is the best way gradually to introduce a baby, particularly a heavily-addicted baby, to a drug-free life. The baby is spared the pains of neonatal withdrawal, receives a diminishing supply of opiate through the breast milk and is eventually weaned naturally from both. 
This is how many mothers cope with the situation, especially those who fear that social workers will remove their babies, as many do. They conceal their drug-taking throughout pregnancy, probably with husband or boyfriend smuggling drugs into the lying-in ward. As a profession we should feel ashamed that mothers have so little confidence in us and so much fear. The lack of confidence comes partly from the fact that the addict knows immediately if the doctor is ignorant about drug use, and many doctors are. The fear comes from the press, the attitude of so many professional carers, and the fact that many babies have been taken away in the past.

An important subject omitted by Dr Riley is injection. Almost everyone who is heavily addicted to opiates injects. Giving up injecting is as difficult as giving up the drugs themselves, whether in pregnancy or otherwise. What does the caring doctor do about that? Many of the 'good girls' apparently reducing on their daily dose of liquid oral methadone are in fact injecting on the side, often in 'secret' sites. Urine tests will not reveal this unless they inject a different drug, in which case they are probably clever enough to fake the urine test, which is usually easy to do. An addict patient of mine described her care during pregnancy under a doctor at a London teaching hospital. She said, "Dr $\mathbf{X}$ is a lovely doctor, ever so sympathetic. The only trouble is that if she looks after you, you have to get your drugs from the black market, and I always felt that couldn't be good for the baby."

13 Devonshire Place

London WIN IPB

\section{DeAr SiRs}

Dr Riley's paper (Bulletin, November 1987, 11, 362-365) was read with interest. In the United States there appears to be a policy of methadone maintenance throughout the confinement. ${ }^{1}$ Others have suggested treatments varying according to the trimester with stabilising on methadone during the first and then gradual reduction during the second. ${ }^{2}$ If the patient presents as late as the third trimester there is a significant risk that withdrawal of opiates may lead to premature labour, foetal distress, meconium aspiration and foetal death should the mother experience withdrawal symptoms. ${ }^{1,2.3 .4}$

In an effort to prevent this development it is suggested that the mother is maintained on the minimum amount of opiates necessary during this final stage. The risk with this approach, however, is that the new-born infant may experience a withdrawal syndrome characterised by vomiting or diarrhoea, hyperpyrexia, irritability, tremors, inability to sleep between feeds and convulsions. ${ }^{3}$ This syndrome occurs more frequently and is more severe and protracted in babies born to mothers dependent upon methadone as opposed to heroin, the seizure rate for the former group being five times that of the latter. ${ }^{3}$ Consequently we suggest that a case can be made for prescribing heroin to the pregnant drug addict who presents for the first time in the final trimester.

\section{CHRISTOPHER S. ThOMAS} Madeline Osborn

Rawnsley Building

Manchester Royal Infirmary

Manchester

REFERENCES

'SENAY, E. C. (1983) Management of pregnant addicts. In Substance Abuse Disorders in Clinical Practice. Bristol: John Wright, pp 88-94.

${ }^{2}$ Brockington, I. F. \& Kumar, R. (1982) Drug addiction and psychotropic drug treatment during pregnancy and lactation. In Motherhood and Mental Illness. London: Academic Press. pp 239-255.

${ }^{3}$ Herzlinger, R. A., Kandall, S. R. \& Vaughan, H. G. (1977). Neonatal seizures associated with narcotic withdrawal. The Journal of Pediatrics, 4, 638-641.

${ }^{4}$ MADDEN, J. D. \& CHAPPEL, J. N. (1974) Fatal meconium aspiration with maternal narcotic withdrawal. In Developments in the Field of Drug Abuse. Proceedings 1974 of the National Associ. ation for the Prevention of Addiction to Narcotics. (Eds. E. Senay and V. Shorty) Cambridge, Massachusetts: Schenkman, p 428.

\section{Dr Riley replies:}

DeAR SiRS

Drs Thomas and Osborn are correct in stating that the available evidence shows more prolonged and severe withdrawal effects in infants whose mothers are maintained on methadone as opposed to heroin. However, these effects can be mitigated by good neonatal care, and the advantages of using oral methadone are considerable. Our policy has been to maintain patients in the community once the initial assessment has been completed, and it might be considered unwise to increase the supply of injectable heroin and syringes on the drug scene at large by prescribing them for out-patients.

Dr Dally's patients are clearly a very different group from those generally seen at UCH. Those who can afford private consultation and prescription fees are certainly more wealthy and probably more stable than our patients who are often homeless, living on Supplementary Benefit, usually with a criminal record, and with little community support. However, a few patients who have been maintained on a steady dose of methadone for many years have presented for treatment, and even these women have been willing to reduce the dose in pregnancy to minimise the withdrawal effects in their babies. This willingness is perhaps a measure of their attachment to the pregnancy, and of the time spent by medical and nursing staff in careful explanation.

Dr Dally totally overlooks the fact that we are responsible for the treatment of two patients: the foetus as well as the mother. Severe withdrawal symptoms in the infants may include grand mal convulsions: a terrible price to pay for the mother's right to continue a high dosage of opiates. The case she reports gives no details of the opiate dosage or 